\title{
Expert Writers' Recommendations in Economics Research Articles: Implications for the Teaching of English for Academic Purposes
}

\author{
MAY SIAW-MEI LIU \\ Academy of Language Studies, \\ Universiti Teknologi MARA, Malaysia \\ JASON MIIN-HWA LIM \\ Centre for the Promotion of Knowledge and Language Learning, \\ Universiti Malaysia Sabah, Malaysia \\ jasonlim@ums.edu.my
}

\begin{abstract}
The presentation of economics research results often constitutes the climax of data-driven research articles in the discipline, but how writers make recommendations based on their results remains a fertile area for an in-depth investigation. To date, no research has been conducted to ascertain the extent to which economics researchers incorporate such recommendations, and how they use language resources to perform the communicative functions involved. Our genre-based study employed the Swalesian move-step analytical framework to examine the occurrence of this pivotal rhetorical category, which makes suggestions based on research findings in economics. This largely qualitative analysis was triangulated via interviews with specialist informants in the field. Our results have shown that recommendations, being a quasi-obligatory move that comprises two noteworthy optional steps, are strategically linked with not only research results but also limitations of the research being reported. The expert writers employ a wide spectrum of language resources, particularly adjectives depicting indeterminacy and noun phrases denoting industrial and policy implications, to tacitly accentuate the value of their results. In regard to pedagogical implications, it is suggested that instructors devise exercises requiring novice writers to construct sentences involving suggestion indicators and verb phrases signalling epistemic modality while guiding learners to make recommendations for future research. With respect to recommendations for practical applications, text-completion exercises may be designed to familiarise learners with the use of active clauses containing nominalisations, which are largely intended to minimise self-mentions and increase objectivity while proposing actions to be taken in real-life settings.
\end{abstract}

Keywords: English for academic purposes; discourse analysis; genre analysis; academic writing; recommendations

\section{INTRODUCTION}

It is widely acknowledged that the research article (RA) constitutes one of the main channels needed to communicate research results to the rest of the academic fraternity (Dahl, 2009; Swales, 2004). Given that it is the "central genre of knowledge production" (Yang \& Allison, 2003, p. 365), the academic discourse community is understandably concerned about guarding the quality and standard of the research article, which can be seen in relation to how the academic community imposes specific discoursal conventions on their writers (Swales, 2004). Knowledge of such academic conventions in the writing of research articles in English is particularly needed in situations where novice writers working in bilingual and multilingual settings are expected to get their papers accepted for publication (Cargill \& Burgess, 2017; Li \& Flowerdew, 2020; Xu \& Nesi, 2019). Nonetheless, academic research writing has been acknowledged by many as a complex process involving different underlying conventions which affect the language, structure, style and treatment of information that are often influenced by preferred disciplinary practices (Creswell, 2015). Due to the complexities involved in writing research articles, previous researchers in the field of English for Academic Purposes (e.g., Hirano, 2009; Lim, 2019; Samraj, 2002; Swales, 2004) have devoted 
considerable effort and resources to study how the research genre can be comprehended and produced to meet the expectations of various academic communities.

It is widely known that one method of analysing the research article (RA) which has received global acceptance is Swales' $(1990,2004)$ robust move-step analytical framework. Initially developed to analyse the Introduction section of a research report, this two-layer framework provides a "thick description" of language (Bhatia, 1993, p. 5) and has been used by numerous researchers to analyse different sections of the RA (Basturkmen, 2012; del Saz Rubio, 2011; Li \& Ge, 2009; Ozturk, 2007; Lim, 2014; Peacock, 2002; Posteguillo, 1999). The focus of past studies into the RA have ranged from the entire RA (Kanoksilapatham, 2005; Koutsantoni, 2006; Li \& Ge, 2009; Lin \& Evans, 2012) to smaller rhetorical sections (Cross \& Oppenheim, 2006; Peacock 2002; Stotesbury, 2003; Swales 2004; Yang \& Allison 2003) and individual moves (Lim, 2017; Shehzad, 2008). Through these studies, various models and generic structures of the research article have been proposed.

One particular component that is especially interesting in move-step analyses of RAs is the move which presents the implications of research findings (Brett, 1994). While most empirical papers are expected to present research results, it is interesting to examine how researchers make recommendations or suggestions based on their results. While past studies have examined this particular move about how researchers discuss the implications of their results (Kanoksilapatham, 2005; Yang \& Allison, 2003), further explorations appear necessary because of uncertainties emerging as a result of disciplinary variations. So far as economics research is concerned, one particular aspect that merits attention is connected with how economics researchers incorporate and manipulate recommendations in relation to their research results and other associated information elements. In particular, this paper aims to explore how writers of economics empirical research articles present the implications of their research findings in the RA.

Some previous researchers have attempted to study the generic structure and language used in economics RAs. For instance, Lakic (2010) studied the Introduction sections of economics RAs and proposed a four-move structure based on an older framework suggested by Swales (1990). Liu and Lim (2014, p. 16) also presented findings on the move which economics writers use to evaluate their own empirical research, and proposed three steps for this move, consisting of (i) "comparing findings with a hypothesis", (ii) "indicating limitations of the research", and (iii) "indicating significance of the research". Notwithstanding the contributions of these studies to the teaching of English for specific purposes (ESP) to second language (L2) learners, the problem that remains is that we do not have sufficient detailed information on how economics researchers use specific language resources to make findingsbased recommendations. Given that "most academic writing courses are expected to be based on the needs of L2 writers" in a specific discipline (Cortes, 2019, p. 1), it would be necessary to conduct an in-depth investigation into how expert writers use language resources for a specific communicative purpose, such as making recommendations, so that relevant information on language use can be shared with instructors teaching the learners concerned.

In view of the research gaps and the need to resolve the problem associated with language instruction explained above, this study used the analytical framework proposed by Swales (2004) to (i) examine the prevalence of such recommendations, and (ii) explore how they are made using salient linguistic resources. The research questions used to guide this study are indicated as follows:

(1) To what extent do economics researchers make recommendations based on their findings in empirical research articles?

(2) How do economics researchers employ language resources to perform the communicative functions in making recommendations based on their findings? 
While the first research question sought some quantitative data on the frequency of recommendations, the second research question, being the major research question, sought qualitative data that illustrates how the rhetorical move is performed linguistically.

\section{LITERATURE REVIEW}

An important feature of interest in this study is the position of the move which indicates research-based recommendations. To understand this, it is necessary to examine existing conventions with regard to the division of units of presentation in the research article. Although it has been reported that the 'Introduction-Methods-Results and Discussion-Conclusion' $(\mathrm{IM}[\mathrm{RD}] \mathrm{C})$ structure is common in some disciplines (Ye, 2019), existing literature indicates that in modern research writing, the standardised division of RAs into the 'IntroductionMethod-Results-Discussion' (IMRD) structure is still often used (Bruce, 2008; Cotos et al., 2015; Li \& Ge, 2009; Loi \& Lim, 2019). In fact, attention is generally focused on "papers that contained the content of a standard four-part organization", rather than those presented in other structures, or others that "included a unique and distinctive sectioning format" (Omidian et al., 2021). It has been noted that research articles in the IMRD structure do not necessarily have obvious headings as writers have a range of lexical choices to represent these sections. Table 1 shows the common lexical representations for typical IMRD sections in the RA.

TABLE 1. Common lexical representations of IMRD sections (Brett, 1994, pp. 48-49; Lim, 2006)

\begin{tabular}{ll}
\hline \multicolumn{1}{c}{$\begin{array}{c}\text { Conventional RA } \\
\text { Section }\end{array}$} & \multicolumn{1}{c}{ Lexical representation } \\
\hline Introduction & Introduction / Theoretical Perspectives / Models / Recent Research/(Unlabelled) \\
Method & Method (in a majority of articles) / Data and Method / Methodology / Data and \\
& Measurement / Research Setting / Research Strategy/The Study/Research Method(s) \\
Results & Results / Findings / Analysis and Results / Data Analysis \\
Discussion & Discussion / Discussion and Conclusion / Summary \\
\hline
\end{tabular}

As mentioned above, if the move which discusses implications of research results appears, it tends to be found in the final section(s) of the RA, under recommendation-related sectional headings. This explains why Weissberg and Buker (1990) and Swales (1990) have suggested that information tended to flow in a 'specific-to-general' orientation towards the end of the RA. This means that information tends to increase in generality as it enters the Discussion section.

In this regard, previous researchers (Dahl, 2009; Lakic, 2010) have attempted to provide some genre descriptions of economics RAs. To our knowledge, however, there has not been any description focusing on this particular move which discusses implications of economics research results. Our initial examination of literature indicates that a suggestion of future research is not the only recommendation that authors can provide after obtaining their results. For instance, it was found that researchers in the field of Medicine may include steps such as "indicating research implications" and "promoting further research" in a concluding move labelled as "stating research conclusions" (Nwogu, 1997, p. 35). As this move appeared in most RAs in Nwogu's study of Medical RAs, it seems that Medical researchers generally indicate research implications and/or further research as part of their conclusion. This is consistent with Klein and Reiser's (2014, p. 34) recommendation that implications of findings be placed "near the end of a journal article". However, it needs to be pointed out that 'indicating research implications' [which could also mean 'generalisation' according to Weissberg and Buker (1990)] and 'promoting further research' have been placed under one move (i.e., 'stating research implications') in Nwogu's (1997) study of Medical Discussion sections, and no 
specific percentage/proportion of articles containing 'promoting further research' was reported.

The aforementioned move on recommendations has been identified in the RAs of other fields of study although different functional labels have been used. To be specific, the word 'deductions from research' has been used by Yang and Allison (2003) in their investigations into the Discussion sections of research reports in applied linguistics, but in this paper the term is avoided because 'deduction' has also been used to refer to generalisation (to the entire population) based on the results (obtained from a sample) in other studies. Hopkins and Dudley-Evans (1988, p. 118), for instance, defined "deduction" as "a claim about the generalisability of particular results" (which is different from a type of "recommendation" in which "the writer makes suggestions for future work"). At this juncture, findings obtained in previous genre-based discourse analyses (relating to findings-based recommendations) will be presented via Tables 2 and 3 to illustrate the theoretical framework needed for examining this rhetorical move. What is noteworthy about Table 2 is not restricted to just the existence of disciplinary differences in the RA genre, as it suggests some possible tendencies in the inclusion of recommendations across different disciplines. In other studies, conducted by Kanoksilapatham (2005) and Joseph and Lim (2019), a more specific functional label (i.e., 'recommendation/s') was used to refer to recommendations for practical applications and further research (see Table 2).

TABLE 2. Percentages of texts containing recommendations for future research and practical applications across disciplines

\begin{tabular}{|c|c|c|c|c|}
\hline Researcher(s) & Discipline & Move label & Constituent steps under the move & $\begin{array}{l}\text { Percentage of RAs } \\
\text { containing 'recommending } \\
\text { future research' and } \\
\text { 'recommending a practical } \\
\text { application' }\end{array}$ \\
\hline $\begin{array}{l}\text { Yang and } \\
\text { Allison } \\
\text { (2003) }\end{array}$ & $\begin{array}{l}\text { Applied } \\
\text { linguistics }\end{array}$ & $\begin{array}{l}\text { Deductions from the } \\
\text { research }\end{array}$ & $\begin{array}{l}\text { Making suggestions } \\
\text { Recommending further research } \\
\text { Drawing pedagogic implications }\end{array}$ & $\begin{array}{c}\text { (Not stated as an overall } \\
\text { percentage) }\end{array}$ \\
\hline $\operatorname{Lim}(2008)$ & $\begin{array}{l}\text { Manageme } \\
\mathrm{nt}\end{array}$ & $\begin{array}{l}\text { Recommendation/s for } \\
\text { future research }\end{array}$ & $\begin{array}{l}\text { Recommending future research } \\
\text { Justifying recommendations for } \\
\text { future studies }\end{array}$ & 95.0 \\
\hline $\begin{array}{l}\text { Basturkmen } \\
(2012)\end{array}$ & Dentistry & $\begin{array}{l}\text { Implications for further } \\
\text { research } \\
\text { and/or clinical practice } \\
\text { or policy }\end{array}$ & $\begin{array}{l}\text { No subdivision into } \\
\text { 'recommending further research' } \\
\text { and 'recommending a practical } \\
\text { application' }\end{array}$ & 70.0 \\
\hline $\begin{array}{l}\text { Joseph \& Lim } \\
\text { (2019) }\end{array}$ & Forestry & $\begin{array}{l}\text { Deductions from the } \\
\text { research }\end{array}$ & $\begin{array}{l}\text { Recommending further research } \\
\text { Recommending a practical } \\
\text { application }\end{array}$ & 91.7 \\
\hline
\end{tabular}

Table 2 shows that recommendations are incorporated in most of the Discussion sections in different disciplines. While recommendations are found in only $70.0 \%$ of the Discussion sections in Dentistry (Basturkmen, 2012), they are incorporated in a vast majority (more than 90.0\%) of those in management and forestry (Joseph \& Lim, 2019; Lim, 2008). In forestry, in particular, the high degree of prevalence has been ascribed to the possibility that "foresters in the field generally act as the ultimate judges of the utility of the new knowledge generated through research" (Joseph \& Lim, 2019, p. 141), thus explaining why the academic community generally expects writers to put forward their suggestions explicitly towards the end of the Discussion section.

Apart from the overall prevalence of recommendations, only some previous researchers have reported on the proportions of articles containing each type of recommendation, especially 'recommending future research' and 'recommending a practical application' (see Table 3). 
TABLE 3. Percentages of Discussion sections containing 'recommending future research' and/or 'recommending a practical application'

\begin{tabular}{|c|c|c|c|}
\hline Researcher(s) & Discipline & $\begin{array}{c}\text { Functional label of 'recommending future } \\
\text { research' or 'recommending a practical } \\
\text { application' }\end{array}$ & $\begin{array}{l}\text { Percentage of } \\
\text { RAs } \\
\text { containing the } \\
\text { step }(\%)\end{array}$ \\
\hline \multirow[t]{6}{*}{ Peacock (2002) } & Physics & Recommendations for future research & 30.0 \\
\hline & Biology & & 56.0 \\
\hline & Environmental science & & 44.0 \\
\hline & Business & & 77.0 \\
\hline & Language and linguistics & & 73.0 \\
\hline & $\begin{array}{l}\text { Public and social } \\
\text { administration }\end{array}$ & & 80.0 \\
\hline Kanoksilapatham (2005) & Biochemistry & Suggesting further research & 53.3 \\
\hline $\operatorname{Lim}(2008)$ & Management & Recommendation/s for future research & 95.0 \\
\hline Tessuto $(2015)$ & Law & Recommending further research & 43.0 \\
\hline Loi, Evans, Lim and & Education & Recommendation (for future research) & 65.0 \\
\hline Akkakoson, (2016) & & Suggestion for practical application/s & 70.0 \\
\hline \multirow{2}{*}{ Joseph and Lim (2019) } & Forestry & Recommending further research & 66.7 \\
\hline & & Recommending a practical application & 81.7 \\
\hline
\end{tabular}

In forestry, in particular, 'recommending a practical application' was reported to be found in most of the Discussion sections in education (Loi et al., 2016) and forestry (Joseph \& Lim, 2019). It has been found that 'recommending a practical application' appears in most (70.0\%) of the Discussion sections in education (Loi et al., 2016), and even a vast majority $(81.7 \%$ ) of those in forestry (Joseph \& Lim, 2019); however, its prevalence was not specifically reported in these past studies. Unlike 'recommending a practical application', 'recommending future research' is reported in a larger number of studies. The prevalence of 'recommending future research' varies markedly across different hard sciences. While it is included in only a minority of the texts in physics (30.0\%) and environmental science (44.0\%), it is incorporated in most of the Discussion sections in biology (56.0\%), biochemistry $(53.3 \%)$ and forestry (66.7\%) (Joseph \& Lim, 2019; Kanoksilapatham, 2005; Peacock, 2002), which are notably related biological sciences. In particular, it has been reported that the relative rarity of 'recommending further research' in biochemistry RAs could be attributed to the intense competition for research grants in some highly applied sciences, which may have resulted in the researchers' tendency to reserve possible future explorations for themselves (Kanoksilapatham, 2005). In contrast, the relative importance of 'recommending further research' in forestry suggests that "researchers put collaboration and disciplinary advancement before the narrow concerns of competition" (Joseph \& Lim, 2019, p. 142).

Despite the considerable variability in the degrees of prevalence across the hard sciences, the Discussion sections in soft sciences are largely unpredictable. It is obvious that 'recommending future research' occurs in the Discussion sections of most soft sciences (or social science disciplines), such as business (77\%), public and social administration $(80.0 \%)$, management (95.0\%), language and linguistics (73.0\%), and education $(65.0 \%)$, (Kanoksilapatham, 2005; Lim, 2008; Loi et al., 2016; Peacock, 2002). Nevertheless, 'recommending future research' appears in only $43.0 \%$ of the Discussion sections in law (Tessuto, 2015). We are therefore uncertain as to whether 'recommending future research' is generally expected in soft sciences such as economics, which forms the focus of this study. More research needs to be conducted to look into the frequency and prevalence of each type of recommendation in social science disciplines by taking into consideration the difference between recommendations for future research and those intended for practical applications. Overall, our review appears to support the theoretical assumption that variations do exist in the research genre in differing academic disciplines, even though they may be occasionally overlapping disciplines in the same academic cluster. 
Aside from the aspect concerning the prevalence of recommendations, another dimension that deserves some attention in the field of economics is the level of linguistic realisations. It has been found that a high level of linguistic competence is expected from its economics researchers if they wish to publish their research articles in reputed international journals (Lung, 2011). In fact, writers in the field have acknowledged that they encounter difficulties in handling the scholarly language of economics (Paxton, 2007). Given the general need to look into how language resources are used to accomplish various communicative functions in Economics research articles, it is necessary to conduct more research into how a specific communicative move is realised linguistically and linked with another related move. In order to provide substantial information on a specific move, this study focuses on 'making a recommendation' (based on a research result), which constitutes a rhetorical move in the final sections of economics research articles.

\section{METHODOLOGY}

The corpus for this study consisted of 40 RAs selected from five international high impact economics journals indexed in Web of Science and based on the elicited views provided by specialist informants in the field of economics. This means that only journals with high impact values and which were verified as reputable by specialist informants were incorporated in the sample. Based on accepted practice in the field of genre analysis (Lim, 2012; Nwogu, 1997; Posteguillo, 1999), eight RAs were selected randomly from each of the following journals: European Economic Review, Quarterly Journal of Economics, Journal of International economics, The Economic Journal, and Journal of Development Economics. Only empirical data-driven research articles were chosen as they represent an important part of the genre (Peacock, 2002). Special issues were avoided in order to minimise bias due to the specific subject matter expected by the editors (Dahl, 2009; Ozturk, 2007). The selected 40 RAs were then numbered RA1 through RA40.

Swales' $(1990,2004)$ robust two-layer analysis of moves and steps was subsequently used to identify the rhetorical move and corresponding steps which indicate that a writer was discussing implications of his/her research findings. As a move was "a discoursal or rhetorical unit that performs a coherent communicative function in a written or spoken discourse" (Swales, 2004, p. 228), linguistic means were used to identify the moves and steps in the corpus. These linguistic means include discourse markers which indicate boundaries, tenses, modality and lexical references which provide clues to the rhetorical purpose of the writers. To ensure consistency in the analysis, an inter-coder reliability was measured. The first author was the first coder while the second author took the role as the second coder, and both coders were experienced genre analysts who had published their works on move analysis in reputed journals indexed in Web of Science. The reliability of the coding process was measured in terms of "percent agreement", generally defined as "the number of agreements per total number of coding decisions" (Biber et al., 2007, p. 35). To be precise, the number of agreements was defined as the number of coding decisions (made by both coders) that were the same in each dataset comprising 40 texts. The percentage of agreement achieved in the initial round of independent coding was only $82.4 \%$, and a detailed discussion was subsequently conducted to rectify the discrepancies so that correct functional labels could be assigned to each recommendation-related segments based on an eventual consensus reached by both coders.

With regard to frequency, past researchers (Joseph \& Lim, 2018; Kanoksilapatham, 2005) have proposed different cut-off points to determine whether a move was considered a principal move or an optional one. In this study, it was decided that a move and its associated steps which appear in $100 \%$ of the texts be considered an obligatory move, while those which 
appear in $51 \%$ to $99 \%$ of the texts be considered as quasi-obligatory. Those which appear in less than half of the texts were categorised as optional moves or steps (Joseph \& Lim, 2019; Soler-Monreal et al., 2011; Yang \& Allison, 2003).

To provide additional information associated with this largely qualitative analysis, eight specialist informants were interviewed to elicit related views on the rhetorical move. The informants interviewed were selected based on (i) Bhatia's (1993, p. 34) criterion which required that a specialist informant should be a "practicing member of the disciplinary culture in which the genre is routinely used", and (ii) Lim and Luo's (2020) criterion that each specialist informant should ideally hold doctoral degrees in their field of study and have published their works in high impact journals indexed in Web of Science and Scopus. However, it needs to be first acknowledged here that not every informant provided related information on each specific aspect observed in this study, and as such, in this paper, statements provided by the specialist informants will be quoted only if they are related to the aspects being observed. Overall, a total of eight specialist informants were interviewed, and they were from universities in Singapore, New Zealand and Malaysia. Face-to-face interviews were conducted with informants in their respective universities, and the information elicited was digitally recorded and transcribed to facilitate interpretation. The specialist informants were then labelled as Specialist Informants A through H (SIA through SIH) in this paper.

\section{RESULTS AND DISCUSSION}

Our genre-based textual analysis has shown that 'making a recommendation' (based on a research result) constitutes a rhetorical move that focuses on (i) drawing readers' attention to some possible avenues for future research signalled by the newly obtained results, and (ii) arousing readers' interest in the linkages between the writers' research outcomes and some positive contributions which have been considered worth foregrounding in their attempt to enhance the publishability of the works. This finding is well corroborated by two of the eight specialist informants. SIB and SID, in particular, were of the view that an implication of research results should generally appear in the form of (i) "recommendations for other researchers" so as to make it possible for them "to conduct further research", and/or (ii) "recommendations for economic policymakers" which will help them "take corrective measures". In this study, the functional label assigned to this move is "making a recommendation', which semantically covers the communicative functions of the two steps that fall under it. The two steps identified to capture the discursive elements of this move are Step 1 (i.e., 'recommending further research'), and Step 2 (i.e., 'recommending a practical application').

With respect to the extent to which recommendations are incorporated by economics researchers, Table 4 shows the frequencies of occurrence of the constituent steps associated with such recommendations. This means that the presence of the move is examined in terms of the presence of each of the two steps in every RA. Step 1 (i.e., 'recommending further research') appears in $35.0 \%$ of the corpus, while Step 2 (i.e., 'recommending a practical application') occurs in $40.0 \%$ of the corpus. 
3L: Language, Linguistics, Literature ${ }^{\circledR}$ The Southeast Asian Journal of English Language Studies Vol 27(3), September 2021 http://doi.org/10.17576/3L-2021-2703-02

TABLE 4. Frequencies of constituent steps in 'making a recommendation' based on research results

\begin{tabular}{lccc}
\hline $\begin{array}{c}\text { Number and percentage of research } \\
\text { articles }\end{array}$ & $\begin{array}{c}\text { Step 1: } \\
\text { Recommending further } \\
\text { research }\end{array}$ & $\begin{array}{c}\text { Making a recommendation based on a result } \\
\text { Step 2: }\end{array}$ & Total \\
\hline $\begin{array}{l}\text { No. of occurrences } \\
\text { No. of RAs with the move/step }\end{array}$ & 19 & 21 & 40 \\
$\begin{array}{l}\text { Percentage (\%) of RA with the } \\
\text { move/step }\end{array}$ & 14 & 16 & 28 \\
\hline
\end{tabular}

Overall, recommendations (including both types) appear in most $(70.0 \%)$ of the economics RAs. Although each of these two steps is optional (rather than quasi-obligatory), their combined effect in the economics RAs is noteworthy given that recommendations are needed in the majority of the economics research articles. On the basis of the overall frequency obtained, it is interesting to note that this move constitutes a quasi-obligatory move in the corpus. With respect to the position of this move, the headings for the final sections of empirical economics RAs tend to reflect some standardisation in the field, although headings for other sections throughout the RAs may vary considerably. Recommendations are found to be predominantly present in the concluding sections of the economics RAs. To be specific, writers generally end their RAs with a closing section called 'Conclusion', 'Conclusions' or a similar variant, as shown in Table 5.

TABLE 5. Lexical choices denoting the headings of the final sections of empirical economics Ras

\begin{tabular}{lcc}
\hline Heading & Number of RAs in the corpus with this heading & Percentage \\
\hline Conclusion & 15 & $37.5 \%$ \\
Conclusions & 20 & $50.0 \%$ \\
Concluding Remarks & 2 & $5.0 \%$ \\
Conclusion and Policy Implications & 1 & $2.5 \%$ \\
Discussion and Conclusion & 1 & $2.5 \%$ \\
Final Remarks & 1 & $2.5 \%$ \\
\hline
\end{tabular}

When recommendations are employed in economics RAs, they are incorporated mostly in the final sections of the RA under headings such as 'Conclusion(s)' or 'Concluding Remarks'. In $85.7 \%$ of the RAs containing such results-based recommendations, this move constitutes the closing move for the entire article. In this regard, SIB and SID pointed out that an application of research results should be incorporated in the final section of a research article. SIC, however, was of the view that the final section of an RA should "discuss the implications (regarding) what policy-makers should do" and propose future studies in a bid to address what is missing. Steps 1 and 2 occur in $35.0 \%$ and $40 \%$ of the economics research articles respectively, thus suggesting that economists are almost equally concerned about (i) how their research outcomes may impact the directions in which high impact research in their research domain may develop, and (ii) the importance of associating their research outcomes with what policymakers need to implement in the real world.

\section{STEP 1: RECOMMENDING FURTHER RESEARCH}

When writers recommend further research, they are in essence encouraging more research work to be conducted in an area related to their own research focus in a quest to further develop knowledge in the discipline. Table 6 shows examples of these communicative strategies employed to recommend further research. 
TABLE 6. Communicative strategies in recommending further research

\begin{tabular}{|c|c|}
\hline $\begin{array}{l}\text { Communicati } \\
\text { ve strategy }\end{array}$ & Instance of recommending further research \\
\hline $\begin{array}{l}\text { Making a } \\
\text { claim about a } \\
\text { pressing need } \\
\text { to fill a gap } \\
\text { through a } \\
\text { resolution to } \\
\text { an issue that } \\
\text { has remained } \\
\text { unanswered }\end{array}$ & $\begin{array}{l}\text { Thus, these latter results still await further investigation. (RA7: 1121) } \\
\text { Further study on the relative reliability of various components of the international accounts is } \\
\text { necessary to shed light on these and other theories of current account sustainability. (RA11: 1526) } \\
\text { For future research, a number of open questions could be addressed. First, government revenue } \\
\text { and expenditure could be disaggregated further... Second, it would be useful to deepen the } \\
\text { empirical analysis by introducing...Finally, there are reasons for believing that the financial } \\
\text { market's treatment of spending and revenue...(RA27: 1983) } \\
\text { The results from this article cannot readily be integrated into these models, so further work is } \\
\text { needed to assess whether the oil shocks led to the replacement of a large fraction of the capital } \\
\text { stock...(RA28: 2008) } \\
\text { Thus, the key issue of causality in the democracy-growth nexus remains open. We believe that } \\
\text { given the ongoing debate on the potential merits and drawbacks of political openness in the Middle } \\
\text { East, Asia and Africa the issue of causality, albeit challenging, deserves future research. (RA29: } \\
\text { 1548) } \\
\text { The results from this article cannot readily be integrated into these models, so further work is } \\
\text { needed to assess whether the oil shocks led to the replacement of a large fraction of the capital } \\
\text { stock and whether this mechanism explains the possibly large effects of energy prices on asset } \\
\text { values. (RA28: } 2008 \text { ) }\end{array}$ \\
\hline $\begin{array}{l}\text { Highlighting } \\
\text { an appeal to } \\
\text { investigate a } \\
\text { selected topic } \\
\text { in a specific } \\
\text { domain }\end{array}$ & $\begin{array}{l}\text { We nevertheless outline a number of suggestions for future work. First, the ways in which... Our } \\
\text { dataset provided some new control variables for entrepreneurial firm quality and VC fund quality; } \\
\text { future work might consider more refined control variables with more detailed data. Further } \\
\text { empirical research along these lines could also consider investor valuations practices and due } \\
\text { diligence reviews, as well as... Further empirical work in this regard might also consider sources } \\
\text { of funds in the... (RA3: } 1237 \text { ) } \\
\text { If the response of incumbents here is anything like the responses in other industries, the study of } \\
\text { preemption and customer loyalty may be a fruitful avenue for future empirical research. (RA14: } \\
1632 \text { ) } \\
\text { An interesting avenue for future research would be to analyse how the positive relationship } \\
\text { between empire and trade impacted productivity and economic growth. (RA25: 1828) }\end{array}$ \\
\hline
\end{tabular}

A notable feature that has been identified is related to how writers propose further research in Step 1 by indicating two differing levels of strength. Writers may (i) indicate a pressing need to fill a gap (which constitutes a robust recommendation aimed at seeking a resolution to an issue that has remained unanswered by research in the same area), or (ii) suggest a possible need to be considered by other economics researchers (in the form of a moderate recommendation that highlights an appeal to further investigate a selected topic in a specific domain). As shown in Table 6, when writers provide recommendations for future research, the work suggested for future research is highlighted through the use of noun phrases denoting prospective work (e.g., 'further work', 'future research', 'further study') in combination with adjectives depicting indeterminacy or ambiguity (e.g., 'a number of open questions, 'the underlying mechanisms are unclear', 'the key issue...remains open'). In addition, writers use "suggestion indicators" (Lim, 2008, p. 136) in the subject-predicatorobject (SPO) clause structures a verb phrase denoting tentative mulling or deliberation is used to link a noun phrase indicating future research endeavours with a subsequent noun phrase denoting possible investigations (e.g., 'future work might consider more refined control variables...', 'further empirical research along these lines could also consider investor valuations practices...', 'Further empirical work in this regard might also consider sources of funds...'). However, when these verb phrases that express tentative mulling are not used, passive verbs indicating necessity are often employed before noun phrases denoting future works and infinitive phrases specifying the domain to be investigated (e.g., 'further work is needed to assess whether...', 'further work is needed to assess whether...').

Another salient feature of 'recommending further research' is associated with the recurrent use of subject-predicator-complement (SPC) structures in which a stative copular/linking verb (e.g., 'is', 'may be', 'would be', 'remains') is used to link a noun phrase 
denoting an overlooked research domain with a noun/adjective phrase indicating a fertile or fascinating area deserving in-depth investigations (e.g., "further study on the relative reliability...is necessary, 'the study of pre-emption and customer loyalty may be a fruitful avenue', 'an interesting avenue for future research would be to analyse...', 'the key issue of causality in the democracy-growth nexus remains open'), thus subtly implying a sense of urgency in administering a suggested research project.

Table 6 shows that when writers decide not to make a strong recommendation, they may instead present a captivating appeal for further research to be conducted. This explains why attributive adjectives carrying positive connotations are used to pre-modify a noun phrase denoting a research track of interest (e.g., 'a fruitful avenue', 'an interesting avenue') so as to create a favourable impression although what is foregrounded may signal only the suggestive and optional nature of a proposed endeavour.

Alternatively, writers would first acknowledge that their research scope is limited either through admitting some weakness of the study being reported or by specifying their selfdefined research area (see Figure 6).

\begin{tabular}{|c|c|}
\hline Indicating limitations of the research & Recommending further research \\
\hline $\begin{array}{l}\text { Regardless, as discussed we were unable to empirically } \\
\text { distinguish between these two themes due to an inability } \\
\text { to obtain details from the investors as to when the } \\
\text { preplanned exit strategy was revealed to the } \\
\text { entrepreneur...(RA3: 1237) }\end{array}$ & $\begin{array}{l}\text { Further empirical work might shed more light on this } \\
\text { issue if and where new data can be obtained. (RA3: } \\
\text { 1237) }\end{array}$ \\
\hline $\begin{array}{l}\text { From the point of view of assessing the long-run benefits } \\
\text { of policies restricting child labor, however, an obvious } \\
\text { shortcoming of this model is that it takes as given the } \\
\text { distribution of human capital in the economy...(RA4: } \\
1302 \text { ) }\end{array}$ & $\begin{array}{l}\text { In future research, such dimensions as endogenous } \\
\text { fertility and political choice of education quality can be } \\
\text { integrated into the model; the structure presented here } \\
\text { is a minimal framework that may yield its own family of } \\
\text { models in the future. (RA4: 1302) }\end{array}$ \\
\hline $\begin{array}{l}\text { Although our results seem fairly robust, there is always } \\
\text { the concern of omitted variables in cross-country } \\
\text { regressions. The concern that our results reflect the } \\
\text { influence of variables not included in the regressions } \\
\text { affecting both growth...The constitutional classification } \\
\text { we focus on in this paper does not have enough } \\
\text { constitutional time variation for meaningful estimates } \\
\text { from fixed-effect. (RA35: } 241 \text { ) }\end{array}$ & $\begin{array}{l}\text { Future empirical research should try to solve this issue } \\
\text { by, e.g., focusing on different constitutional aspects or } \\
\text { exploiting the new wave of democracies in the Eastern } \\
\text { Europe. (RA35: 241) }\end{array}$ \\
\hline
\end{tabular}

FIGURE 1. Shifts from 'indicating limitations of the research' to 'recommending further research'

The shift from the step that indicates research limitations to the step that makes future recommendations is also consistent with the views shared by our specialist informants. SIA, in particular, has pointed out that economists tend to "talk about shortcomings of your [their] study" in close relation to their recommendations for future research. Likewise, SIC was of the view that writers could recommend "future studies to address certain issues left unaddressed by their work" in a bid to tacitly signal a positive aspect of their studies. As shown in Figure 1, writers normally acknowledge the lack of sufficient details obtained in the current study before moving on to suggest that further empirical data be obtained to comprehensively understand the issue. Alternatively, economists may first acknowledge an undeniable shortcoming of the model being used before proceeding to propose that additional dimensions/aspects (overlooked in the current study) be incorporated in an enhanced model in the future.

\section{STEP 2: RECOMMENDING A PRACTICAL APPLICATION}

Aside from recommending further research to be conducted, writers also recommend practical applications of the results of their study, and this is realised through Step 2 (i.e., 'recommending a practical application'). Our specialist informants were of the view that recommendations for practical applications are generally targeted at policymakers. When these application-related 
recommendations are presented, they appear prominently under headings such as 'implications', 'suggestions' or 'recommendations'. The following examples show how writers associate their findings with applications in the real world:

(1) The policy implication of these combined results is that monitoring bank-specific characteristics is relevant both for evaluating the overall effects on lending and deposits...(RA8: 816)

(2) My empirical findings have rich implications for IPR policies. Public enforcement efforts tend to outperform private ones in light of the fact that, after the loosening of government enforcement, authentic companies have to tolerate a higher level of counterfeiting...(RA13: 1607)

(3) The policy recommendation from these results is clear. One way to reduce excess female mortality and to increase overall education investment in children is to increase the relative earnings of adult women. (RA15: 1281)

(4) Specifically, it suggests that initiatives to encourage trade from developing countries, such as the WTO's Aid for Trade Projects, need to focus heavily on fostering poor countries abilities to meet technical regulations. (RA19: 175)

(5) While our study does not explicitly focus on the effects of customs reform, its findings suggest that limiting discretion of customs officials, introducing systems allowing for verification of import documents or price comparisons with similar products and introducing effective audits of customs officials are likely to lower tariff evasion. (RA22: 221)

(6) This study suggests a number of policy implications for countries seeking to lower their borrowing cost on international capital markets. First, a country can pursue either revenue-based or expenditure-based fiscal adjustments... (RA27: 1983)

The use of noun phrases denoting application of results (e.g., 'The policy implication of these combined results', 'rich implications', 'The policy recommendation from these results') and verb phrases expressing proposals (e.g., 'suggests') signals a shift from the research world back into the real world where writers' findings can be applied. In the written discourse, this is largely consistent with Weissburg and Buker (1990) and Swales' (1990) observation that information presented towards the end of the RA tended to increase in generality. We have found that in economics, the writer normally moves from the narrow focus of his/her research (the abstract or ideal world where variables can be controlled for experiments to be carried out) into the more general territory of the real-world.

When recommendations for practical applications are made, there is an absence of reference to the writer; instead, the findings of the research are presented as the sentencesubject ensued by active that-clauses (e.g., 'it suggests that', 'its findings suggest that'), thus implying that writers have a greater propensity to avoid accentuating their own roles when reallife applications need to be foregrounded. An alternative strategy to avoid self-mention in 'recommending mention is employed via heavy nominalisation in which actions to be taken in real-life contexts are indicated via noun phrases in clause-initial positions (e.g., 'initiatives to encourage trade from developing countries, such as the WTO's Aid for Trade Projects', 'One way to reduce excess female mortality and to increase overall education investment in children', 'limiting discretion of customs officials... and introducing effective audits of customs officials'), which are immediately ensued by suggestion indicators in the form of present-tense verb-infinitive structures (e.g., 'is to increase', 'need to focus', 'are likely to lower'). The writers' avoidance of self-mention in such recommendations and their tendency to use nominalisations prior to suggestion indicators appear to be a strategy intended to tacitly downplay the writers' involvement, thus signalling an objective interpretation of what needs to be executed in real-life settings. 


\section{CONCLUSION}

This study has shown that 'making a recommendation' in economics, as a whole, is quasiobligatory, even though each of the two steps involved in it is optional and used only in specific situations where writers need to demonstrate that they are aware of how their findings can eventually lead to future research endeavours and possible practical applications. This is evident given that in $70 \%$ of the articles in this corpus, at least one form of recommendation emerges as a suggestion-based "deduction" (Yang \& Allison, 2003, p. 376) from the results that have been reported. Overall, it is interesting to note that in $60 \%$ of RAs in the corpus of economics journal papers, recommendations constitute the closing move of the entire article. As such, it can be concluded that in economics, recommendations based on research results are expected to function strategically as a form of closure to the RA. While the findings of this inquiry are generally consistent with those reported in previous studies (Kanoksilapatham, 2005; Peacock, 2002), it is necessary to take note of some variations across disciplines, especially when it comes to the prevalence of each type of recommendation. In fact, it is through a cross-disciplinary comparison that genre analysts can possibly develop a deeper insight into the nature of a discipline in relation to the expectations associated with it.

When both forms of recommendation are taken into consideration, we can see that although the prevalence of 'making a recommendation' (70.0\%) appears to be lower than those in some disciplines such as forestry (Joseph \& Lim, 2019), it is as high as that in Dentistry (Basturkmen, 2012). Such a comparison suggests that even though applied sciences, in general, need to consider immediate applications affecting "human well-being and environmental quality" (Kassouri \& Altıntas, 2020, p. 1), the prevalence of recommendations varies considerably across diverse applied science disciplines. This explains why it is harder to compare the prevalence of recommendations in the RAs on economics, an applied soft science, with those in applied hard sciences. What remains clear is that the spirit of competition, resulting from the researchers' plans on future studies and practical applications, is less intense so far as economics RAs are concerned, thus explaining why the prevalence of 'making a recommendation' in economics, as an applied soft science, is similar to that of a relatively less competitive hard science, such as Dentistry (Basturkmen, 2012).

A closer look at how writers' results may lead to recommendations often requires an examination of each of the two types of recommendation. First, our findings have shown that 'recommending further research' occurs in about a third of the economics research articles, and the figure is akin to that in law, another applied soft science in which more than two-thirds of the RAs do not suggest any avenue for future research (Tessuto, 2015). This, however, differs from other disciplines such as (i) biology, forestry, biochemistry, business, language and linguistics, and education in which writers incorporate recommendations for further research in most of their research articles (Joseph \& Lim, 2019; Kanoksilapatham, 2005; Loi et al., 2016; Peacock, 2002), and (ii) management in which a vast majority of the writers include suggestions for further research (Lim, 2008). In particular, the relative importance of 'recommending further research' in some soft sciences such as education and management, as compared to economics, suggests that economics researchers, in general, demonstrate a lower tendency to dictate how further research endeavours can be attempted by future researchers to further advance knowledge in the same discipline. However, in cases where suggestions for future research become necessary, writers often strategically link their recommendations with the acknowledgement of their own research limitations, in a bid to create an impression that their study has ultimately shed some light on an area for future exploration.

Second, compared to 'recommending further research', 'recommending a practical application' occurs in a higher proportion (40.0\%) of the economics research articles; 
nevertheless such direct reference to real-life utility of current research findings is still rarer compared to those in other disciplines, such as education and forestry in which the majority of the Discussion sections indicate distinctly how their research papers can be applied in the industry or in the world at large (Joseph \& Lim, 2019; Loi et al., 2016). Such findings suggest that although economists, compared to other applied fields of study, have a relatively greater propensity to avoid specifying how their findings have direct implications on real-life utility, they generally expect the "invoked" audience (Ede \& Lunsford, 1984, p. 160) to (i) make a judgement on the possible direction in which the economic situation will develop, and (ii) "actively contribute to the meaning of what they read" (Mitchell \& Taylor, 1979, p. 251) before responding to the preconceptions generated while discussing their research results.

\section{IMPLICATIONS FOR WRITING INSTRUCTION}

While the prevalence of each type of recommendation merits some attention, what appears pedagogically significant is how ESP instructors can design relevant teaching materials using the salient language resources related to recommendations, especially under circumstances where recommendations are unavoidable, and novice writers actually "face linguistic and rhetorical difficulties when writing their academic texts for publication in an L2" (Mur-Dueñas, 2012, p. 55). To expose such writers to the strategy for recommending further research in economics, instructors may have to first identify the areas in which information remains incomplete (after the writers' findings have been reported). Given that "the use of recurring word combinations has been considered a sign of proficient language use of particular registers" (Cortes, 2006, p. 391), ESP instructors may encourage learners to attempt an exercise requiring them to match noun phrases containing adjectives depicting indeterminacy or ambiguity with other noun phrases denoting prospective work. To further familiarise second language learners with suggestions for future research, learners can be encouraged to construct sentences in the SPO structure by completing a gap-filling exercise which involves the use of "suggestion indicators" (Lim, 2008, p. 136) and verb phrases that denote tentative mulling and signal explicit "epistemic modality" (Cheng \& Cheng, 2014, p. 16). Although the SPO structure seems to be just a form of fixed word combinations, writers' "frequent use of fixed expressions" may often "signal competent language use within a register" (Cortes, 2004, p. 398). Alternatively, instructors may highlight the use of an SPC structure in which learners are expected to use attributive adjectives to pre-modify nouns denoting possible research tracks of interest, in a bid to convey an optional sense of suggestion. This explains why the structures suggested above may be used as an initial frame of reference that gradually familiarises novice writers with the conventions expected in making recommendations.

While these adjectives and nouns form the core of recommendations for further research, instructors might consider placing a greater emphasis on noun phrases denoting industrial and policy implications and sentence-subjects which are void of self-reference, when it comes to recommendations for practical applications. This encourages learners to shift back from a research context to a real-life applied setting that involves hardly any reference to the writers themselves. In this case, a text-completion exercise can be devised in such a way that learners are encouraged to use active clauses with nominalisations that overtly foreground the external industrial contexts in which their research results are applicable, thus minimising selfmentions in a bid to increase objectivity while proposing actions to be taken in real-life applications. Using the numerous instances provided in this paper, the aforementioned exercises can be used to raise novice writers' consciousness of how linguistic resources are employed to make relevant recommendations to policy-makers from a practical economic perspective. In brief, the findings of this study have added to our existing knowledge of resultsbased deductions in economics RAs and can assist disciplinary writers in making informed 
choices while writing such recommendations. With respect to the pedagogic value of this study, the linguistic resources identified in making recommendations based on research findings and the associated rhetorical shifts can also be used to help ESP instructors highlight the necessary lexico-grammatical structures needed to write the quasi-obligatory closing move in economics research reports.

\section{ACKNOWLEDGEMENTS}

Many thanks to the Universiti Malaysia Sabah for providing a research grant (SDK-0248-2020) that has helped us obtain related references for this investigation into recommendations in economics research articles. We are indebted to our specialist informants who have given us enlightening and useful inputs.

\section{REFERENCES}

Basturkmen, H. (2012). A genre-based investigation of discussion sections of research articles in Dentistry and disciplinary variation. Journal of English for Academic Purposes, 11(2), 134-144.

Bhatia, V. K. (1993). Analysing genre: Language use in professional settings. Essex: Longman Group U.K. Limited.

Biber, D., Connor, D., \& Upton, T. A. (2007). Discourse on the move: Using corpus analysis to describe discourse structure. Amsterdam: John Benjamins.

Brett, P. (1994). A genre analysis of the Results section of sociology articles. English for Specific Purposes, 13(1), 47-59.

Bruce, I. (2008). Cognitive genre structures in Methods sections of research articles: a corpus study. Journal of English for Academic Purposes, 7(1), 38-54.

Cargill, M., \& Burgess, S. (Eds.). (2017). Publishing research in English as an additional language: Practices, pathways and potentials. University of Adelaide Press. Retrieved July 8, 2021, from https://www.cambridge.org/core/books/publishing-research-in-english-as-an-additional-

language/D5AC383AE6BE6B3517A4CFBB179A7535.

Cheng, W., \& Cheng, L. (2014). Epistemic modality in court judgments: A corpus-driven comparison of civil cases in Hong Kong and Scotland. English for Specific Purposes, 33, 15-26.

Cortes, V. (2004). Lexical bundles in published and student disciplinary writing: Examples from history and biology. English for Specific Purposes, 23, 397-423.

Cortes, V. (2006). Teaching lexical bundles in the disciplines: An example from a writing intensive history class. Linguistics and Education, 17, 391-406.

Cortes, V. (2019). Considering the importance of L2 learners' writing needs. Journal of Second Language Writing, 46, 1-2.

Cotos, E., Huffman, S., \& Link, S. (2015). Furthering and applying move/step constructs: Technology-driven marshalling of Swalesian genre theory for EAP pedagogy. Journal of English for Academic Purposes, $19,52-72$.

Creswell, J. W. (2015). Educational research: planning, conducting and evaluating quantitative and qualitative research (5th ed.). New York: Pearson Education.

Cross, C., \& Oppenheim, C. (2006). A genre analysis of scientific abstracts. Journal of Documentation. 62(4): 428-446.

Dahl, T. (2009). The linguistic representation of rhetorical function: A study of how economists present their knowledge claims. Written Communication, 26(4), 370-391.

Del Saz Rubio, M. M. (2011). A pragmatic approach to the macro-structure and metadiscoursal features of research article introductions in the field of agricultural sciences. English for Specific Purposes, 30(4), 258-271.

Ede, L., \& Lunsford, A. (1984). Audience addressed/audience invoked: The role of audience in composition theory and pedagogy. College Composition \& Communication, 35(2), 155-171.

Hirano, E. (2009). Research article introductions in English for Specific Purposes: A comparison between Brazilian Portuguese and English. English for Specific Purposes, 28, 240-250.

Hopkins, A., \& Dudley-Evans, T. (1988). A genre-based investigation of the discussion sections in articles and dissertations. English for Specific Purposes, 7(2), 113-121.

Joseph, R., \& Lim, J. M. H. (2018). Background information in the Discussion sections of Forestry journals: A case study. GEMA Online Journal of Language Studies, 18(1), 198-216. 
Joseph, R., \& Lim, J. M. H. (2019). Directions for the future: A genre-based investigation into recommendations for further research and practical applications in Forestry. ESP Today, 7(2), 124-147.

Kanoksilapatham, B. (2005). Rhetorical structure of biochemistry research articles. English for Specific Purposes, 24(3), 269-292.

Kassouri, Y., \& Altıntas, H. (2020). Human well-being versus ecological footprint in MENA countries: A tradeoff? Journal of Environmental Management, 263, 1-16.

Klein, J. D., \& Reiser, R. A. (2014). Suggestions for structuring a research article. Journal of Computing in Higher Education, 26, 22-38.

Koutsantoni, D. (2006). Rhetorical strategies in engineering research articles and research theses: Advance academic literacy and relations of power. Journal of English for Academic Purposes, 5(1), 19-36.

Lakic, I. (2010). Analysing genre: Research article introductions in economics. The Journal of Linguistic and Intercultural Education, 3, 83-99.

Li, Y, \& Flowerdew, J. (2020). Teaching English for Research Publication Purposes (ERPP): A review of language teachers' pedagogical initiatives. English for Specific Purposes, 59, 29-41.

Li, L., \& Ge, G. (2009). Genre analysis: structural and linguistic evolution of the English-medium research article (1985-2004). English for Specific Purposes, 28(2), 93-104.

Lim, J. M. H. (2006). Method sections of management research articles: A pedagogically motivated qualitative study. English for Specific Purposes, 25(3), 282-309.

Lim, J. M. H. (2008). Analysing recommendations for future research: An investigation into a hybrid sub-genre. In R. Wilkinson \& V. Zegers (Eds.) Realizing content and language integration in higher education (pp. 131-154). Maastricht: Maastricht University.

Lim, J. M. H. (2012). How do writers establish research niches? A genre-based investigation into management researchers' rhetorical steps and linguistic mechanisms. Journal of English for Academic Purposes, $11(3), 229-245$.

Lim, J. M. H. (2014). Expert writers' descriptions and justifications of research instruments and materials: Using communicative resources to generate promotional effects. Journal of Applied Linguistics and Professional Practice, 11(2), 154-176.

Lim, J. M. H. (2017). Writing descriptions of experimental procedures in language education: Implications for the teaching of English for academic purposes. English for Specific Purposes, 47, 61-80.

Lim, J. M. H. (2019). Explicit and implicit justifications of experimental procedures in language education: Pedagogical implications of studying expert writers' communicative resources. Journal of English for Academic Purposes, 37, 34-51.

Lim, J. M. H., \& Luo, X. (2020). Writing research questions and hypotheses: A genre-based investigation into writers' linguistic resources in social sciences. ESP Today, 8(2), 206-226.

Lin, L., \& Evans, S. (2012). Structural patterns in empirical research articles: A cross-disciplinary study. English for Specific Purposes, 31(3), 150-160.

Liu, M. S. M., \& Lim, J. M. H. (2014). How do writers evaluate their own empirical research? A genre-based inquiry into economics journal papers. Procedia Social and Behavioural Sciences, 134, 13-22.

Loi, C. K., Evans, M.S., Lim, J. M. H., \& Akkakoson, S. (2016). A comparison between Malay and English research article discussions: A move analysis. SAGE Open, 6(2), 1-11.

Loi, C. K., \& Lim, J. M. H. (2019). Hedging in the discussion sections of English and Malay educational research articles. GEMA Online Journal of Language Studies, 19(1), 36-61.

Lung, J. (2011). Discursive hierarchical patterning in economics cases. English for Specific Purposes, 30(2), 138149.

Mitchell, R., \& Taylor, M. (1979). The integrating perspective: An audience-response model for writing. College English, 41(3), 247-271.

Mur-Dueñas, P. (2012). A corpus-based analysis of two crucial steps in business management research articles: The creation of a research space and the statement of limitations. Nordic Journal of English Studies, 11(1), 55-77.

Nwogu, K. N. (1997). The medical research paper: Structure and functions. English for Specific Purposes, 16(2), 119-138.

Omidian, T., Siyanova-Chanturia, A., \& Biber, D. (2021). A new multidimensional model of writing for research publication: An analysis of disciplinarity, intra-textual variation, and L1 versus LX expert writing. Journal of English for Academic Purposes, 53, 1-20.

Ozturk, I. (2007). The textual organisation of research article introductions in applied linguistics: Variability within a single discipline. English for Specific Purposes, 26(1), 25-38.

Paxton, M. (2007). Tensions between textbook pedagogy and the literacy practices of the disciplinary community: A study of writing in first year economics. Journal of English for Academic Purposes, 6(2), 109-125.

Peacock, M. (2002). Communicative moves in the discussion section of research articles. System, 30(4), $479-497$. 
Posteguillo, S. (1999). The schematic structure of computer science research articles. English for Specific Purposes, 18(2), 139-160.

Samraj, B. (2002). Introductions in research articles: Variations across disciplines. English for Specific Purposes, 2l(1), 1-17.

Shehzad, W. (2008). Move two: Establishing a niche. Iberica, 15, 25-50.

Soler-Monreal, C., Carbonell-Olivares M., \& Gil-Salom, L. (2011). A contrastive study of the rhetorical organisation of English and Spanish PhD thesis introductions. English for Specific Purposes, 30(1), 417.

Stotesbury, H. (2003). Evaluation in research article abstracts in the narrative and hard sciences. Journal of English for Academic Purposes, 2(4), 327-341.

Swales, J. M. (1990). Genre analysis. English in academic and research settings. Cambridge: Cambridge University Press.

Swales, J. M. (2004). Research genres. Explorations and applications. Cambridge: Cambridge University Press.

Tessuto, G. (2015). Generic structure and rhetorical moves in English-language empirical law research articles: Sites of interdisciplinary and interdiscursive cross-over. English for Specific Purposes, 37(1), 13-26.

Weissberg, R., \& Buker, S. (1990). Writing up research. Experimental research report writing for students of English. Englewood Cliffs, NJ: Prentice Hall.

$\mathrm{Xu}, \mathrm{X}$., \& Nesi, H. (2019). Evaluation in international research articles: A comparison of the strategies used by Chinese and British authors. Text \& Talk, 39(6), 33-53.

Yang, R., \& Allison, D. (2003). Research articles in applied linguistics: Moving from Results to Conclusions. English for Specific Purposes, 22(4), 365-385.

Ye, Y. (2019). Macrostructures and rhetorical moves in energy engineering research articles written by Chinese expert writers. Journal of English for Academic Purposes, 38, 48-61. 